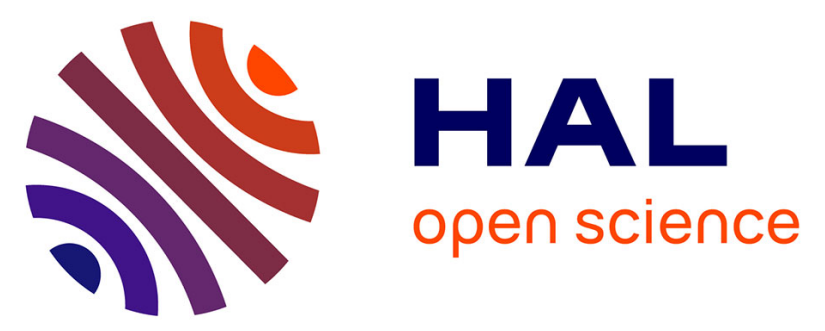

\title{
A detailed TEM and SEM study of Ni-base alloys oxide scales formed in primary conditions of pressurized water reactor
}

\author{
Mohamed Sennour, Loic Marchetti, Frantz Martin, Stéphane Perrin, Régine \\ Molins, Michèle Pijolat
}

\section{To cite this version:}

Mohamed Sennour, Loic Marchetti, Frantz Martin, Stéphane Perrin, Régine Molins, et al.. A detailed TEM and SEM study of Ni-base alloys oxide scales formed in primary conditions of pressurized water reactor. Journal of Nuclear Materials, 2010, 402 (2-3), pp.147-156. 10.1016/j.jnucmat.2010.05.010 . hal-00507516

\section{HAL Id: hal-00507516 https://hal.science/hal-00507516}

Submitted on 4 Aug 2010

HAL is a multi-disciplinary open access archive for the deposit and dissemination of scientific research documents, whether they are published or not. The documents may come from teaching and research institutions in France or abroad, or from public or private research centers.
L'archive ouverte pluridisciplinaire HAL, est destinée au dépôt et à la diffusion de documents scientifiques de niveau recherche, publiés ou non, émanant des établissements d'enseignement et de recherche français ou étrangers, des laboratoires publics ou privés. 


\title{
A detailed TEM and SEM study of Ni-base alloys oxide scales formed in primary conditions of pressurized water reactor
}

\author{
MOHAMEd SENNOUR(1)*, LoÏC MARCheTti(2), FrANTZ MARTIN(2), STÉPHANE PeRRIN(2), \\ RÉGINE MOLINS ${ }^{(1)}$, MiCHÈle PIJ OLAT ${ }^{(3)}$
}

(1) MINES, ParisTech, Centre des Matériaux, UMR CNRS 7633, B.P. 87, 91003 Evry Cedex, France

(2) CEA ; DEN ; DPC ; SCCME ; Laboratoire d'Etude de la Corrosion Aqueuse ; F91191 Gif-sur-Yvette ; France

(3) Ecole Nationale Supérieure des Mines de Saint Etienne ; Centre SPIN ; Département ProcESS ; LPMG -UMR CNRS 5148 ; 158 Cours Fauriel ; 42023 Saint-Étienne Cedex 2 ; France

\begin{abstract}
The oxide film formed on nickel-based alloys in pressurized water reactors (PWR) primary coolant conditions $\left(325^{\circ} \mathrm{C}\right.$, aqueous media) is very thin, in the range of $1-100 \mathrm{~nm}$ thick, depending on the surface state and on the corrosion test duration. The nature and the structure of this scale have been investigated by Transmission Electron Microscopy (TEM) and Scanning Electron Microscopy (SEM). TEM observations revealed an oxide layer divided in two parts. The internal layer was mainly composed of a continuous spinel layer, identified as a mixed iron and nickel chromite $\left(\mathrm{Ni}_{(1-x)} \mathrm{Fe}_{x} \mathrm{Cr}_{2} \mathrm{O}_{4}\right)$. Moreover, nodules of $\mathrm{Cr}_{2} \mathrm{O}_{3}$, with a size about $5 \mathrm{~nm}$, were present at the interface between this spinel and the alloy. No chromium depletion was observed in the alloy, at the alloy/oxide interface. The external layer is composed of large crystallites corresponding to a spinel structure rich in iron $\left(\mathrm{Ni}_{(1-z)} \mathrm{Fe}_{(2+z)} \mathrm{O}_{4}\right)$ resulting from precipitation phenomena. SEM and TEM observations showed a link between the nucleation and/or the growth of crystallites of nickel ferrite and the crystallographic orientation of the substrate. A link between the presence of surface defects and the nucleation of the crystallites was also underlined by SEM observations. Partially hydrated nickel hydroxide, was also observed by TEM in the external scale. Based on these results, some considerations about the mechanism of formation of this oxide layer are discussed.
\end{abstract}

Keywords:

TEM ; SEM ; nickel ; based alloys ; pressurized water reactors ; PWR ; oxide film ; corrosion ; high temperature ; high pressure water ; steam generators ; $S G$

\section{Introduction}

The corrosion behavior of nickel-base alloys in high temperature and high pressure water were studied in order to simulate corrosion of steam generators (SG) of pressurized water reactors (PWR) in the primary circuit, i.e. in an aqueous medium at a temperature between $285-325{ }^{\circ} \mathrm{C}$ and a hydrogen concentration between 25 and $50 \mathrm{~cm}^{3} \mathrm{~kg}^{-1}$ (NTP). In these conditions, the passivity of these alloys is due to the formation of a protective oxide film, which acts as a diffusion barrier and consequently reduces the corrosion rate. In fact, the passive film reduces the release of corrosion products, as nickel cations, in primary water. ${ }^{58} \mathrm{Ni}$ released in the primary circuit is activated into ${ }^{8} \mathrm{Co}$ in the nuclear core under neutronic

* Auteur à qui la correspondance devait être adressée : mohamed.sennour@ensmp.fr 
flux, increasing the global radioactivity of the primary circuit of PWR. For safety reasons for the maintenance staff, the control and restriction of the release of nickel species in the primary circuit is of crucial importance. Therefore the knowledge of the nature and the structure of passive films formed on these alloys is essential for a better understanding of the mechanisms governing the phenomena of oxidation and release.

Many published papers describe the oxide film growing on nickel-base alloys as having a duplex structure [1], [2], [3], [4], [5], [6], [7] and [8]. This duplex oxide has been described as an inner Cr-rich layer and an outer layer consisting of scattered octahedral Fe-rich crystals [2], [5] and [8] attributed to precipitation phenomena, which occurs in saturated media [3] and [6]. The size of these crystallites varies in the range of $100 \mathrm{~nm}$ to $1 \mu \mathrm{m}$ [5], [9], [10], [11] and [12]. On the contrary, when corrosion tests were carried out in continuously cleaned and purified media, the crystallite density was drastically decreased [6] in agreement with unsaturated conditions. In these conditions, the duplex morphology was characterized as an internal $\mathrm{Cr}$ rich layer and a thicker external layer rich in $\mathrm{Cr}$ and $\mathrm{Ni}$ [4] and [6].

If we consider that the duplex structure designation refers to a layer of scattered precipitated crystallites surmounting a continuous and protective oxide film, the question of a multi-layer structure for the protective oxide film can be asked. In this way, Machet et al. [5] suggests a $\mathrm{Cr} / \mathrm{Ni}$ atomic ratio around two in the inner oxide film, consistent with the external layer described by Carrette et al. [4]. In a more recent paper [7], a duplex structure composed by an inner $\mathrm{Cr}_{2} \mathrm{O}_{3}$ layer and an outer $\mathrm{Ni}(\mathrm{OH})_{2}$ layer was suggested based on an XPS study. Some authors [8], [10], [12], [13] and [14] also showed the presence of a chromium depleted layer in the alloy at the oxide alloy interface. Facing these different works, the nature of the passive film formed on nickel-base alloys in PWR primary water conditions is still not well defined. The objective of this work is thus to obtain a better understanding of the passive film structure by using SEM and advanced TEM techniques.

\section{Materials and methods}

\section{II.1. Materials}

Two different alloys were investigated in this work. The first one is the Alloy 690. It is one of the typical Ni-base alloys used for the manufacturing of steam generators tubes. The second one is a "model" alloy called $\mathrm{Ni}-30 \mathrm{Cr}$ whose chromium content is close to the composition of Alloy 690 but $\mathrm{Ni}-30 \mathrm{Cr}$ was quasi iron free. As a consequence, this "model" material is ideal to study the role of iron on the structure of the oxide layer. The compositions of both alloys are given in Table 1. On Alloy 690, a complementary heat treatment has been performed with a tempering at $730^{\circ} \mathrm{C}$ during $5 \mathrm{~h}$ and $30 \mathrm{~min}$, followed by an air cooling. No heat treatment was performed on alloy $\mathrm{Ni}-30 \mathrm{Cr}$.

Table 1: Compositions (in wt.\%) of alloys 690 and $\mathrm{Ni}-30 \mathrm{Cr}$ studied in this work.

\begin{tabular}{|c|c|c|c|c|c|c|c|c|c|c|c|c|}
\hline \multirow{2}{*}{ Alloys } & \multicolumn{12}{|c|}{ Contents of different alloying elements/wt.\% } \\
\hline & Ni & $\mathrm{Cr}$ & Fe & C & Co & Mn & Al & Ti & $\mathrm{Cu}$ & $\mathbf{S i}$ & $\mathbf{S}$ & $\mathbf{P}$ \\
\hline 690 & 59.31 & 29.20 & 9.94 & 0.018 & 0.014 & 0.31 & 0.13 & 0.27 & $<0.002$ & 0.27 & $<0.0005$ & 0.007 \\
\hline Ni-30Cr & 69.15 & 30.35 & 0.25 & 0.002 & - & 0.02 & 0.06 & 0.04 & - & 0.1 & 0.0009 & - \\
\hline
\end{tabular}

The sample are coupons with dimensions of $30 \times 20 \times 2.5 \mathrm{~mm}$ whose surfaces were prepared and mechanically mirror-polished with $\mathrm{SiC}$ paper up to grade 1200 , diamond paste up to $1 \mu \mathrm{m}$ and alumina gel finish (OPA). Then samples were cleaned first with distilled water and then with an ethanol-acetone binary mixture in ultrasonic bath. Scanning Electron Microscopy (SEM) observations, after electrolytic attack with an orthophosphoric acid solution, revealed a grain size about $25 \mu \mathrm{m}$ for Alloy 690 and superior to $100 \mu \mathrm{m}$ for alloy $\mathrm{Ni}-30 \mathrm{Cr}$.

\section{II.2. Corrosion experiments}

The corrosion experiments were performed at $325{ }^{\circ} \mathrm{C}$, under 155 bars in a recirculation autoclave with a flow rate of $17 \mathrm{~L} \mathrm{~h}^{-1}$. This testing device is presented in broad outline on 
Figure 1 and can be divided in three parts. The samples were exposed in the autoclave, in the high temperature $\left(325^{\circ} \mathrm{C}\right)$ and high pressure (155 bars) part of the experimental device.

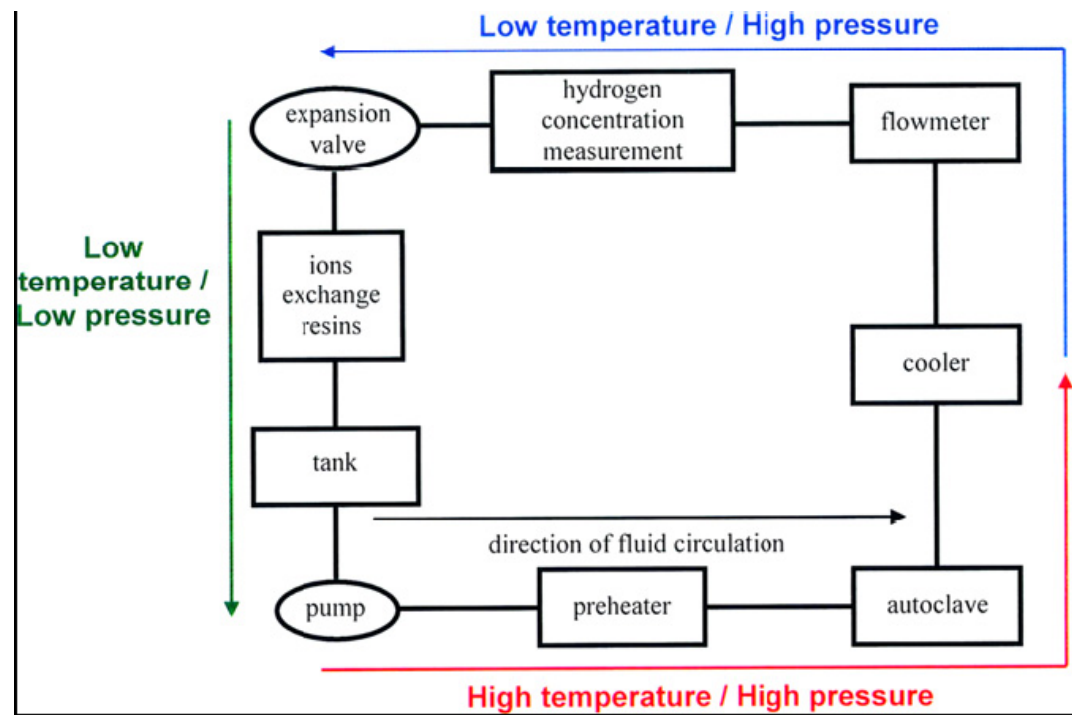

Figure 1: Schematic representation of recirculation autoclave.

Different corrosion durations were investigated, from 66 to $858 \mathrm{~h}$. The aqueous solution contained $2 \mathrm{ppm}$ lithium ( $\mathrm{LiOH})$ and $1000 \mathrm{ppm}$ boron $\left(\mathrm{H}_{3} \mathrm{BO}_{3}\right)$, in equilibrium with a hydrogen overpressure of $0.29 \pm 0.02 \mathrm{bar}$. This overpressure ensures a dissolved $\mathrm{H}_{2}$ concentration of $1.3 \times 10^{-3} \mathrm{~mol} \mathrm{~L}^{-1}$ at $325{ }^{\circ} \mathrm{C}$ (corresponding to a molar fraction of $3.4 \times 10^{-5}$ ) and a low oxygen content $\left(\mathrm{O}_{2}<10 \mathrm{ppb}\right)$.

Basically, the media under the hydrogen overpressure is injected from the tank and put at high pressure ( 155 bar) between a pump and an expansion valve (high temperature/high pressure and low temperature/low pressure parts). The pressurized water is then pre-heated at $325{ }^{\circ} \mathrm{C}$ before arriving in the autoclave where the samples are maintained at $325{ }^{\circ} \mathrm{C}$ and corroded for various periods. On the downstream side of the autoclave, the aqueous solution is cooled down and crosses a flowmeter, which regulates the pump, and the hydrogen concentration is measured by an orbisphere provided by Hach Ultra ${ }^{\circledR}$ (low temperature/low pressure part). The high pressure part of the recirculation loop ends with the expansion valve just before the ion-exchange resins (low temperature/high pressure part), which only works at low pressure (and low temperature). The aim of the ion-exchange resins is to maintain the concentration of metallic cations in the liquid phase as low as possible to avoid precipitation. Their efficiency is much dependent on the temperature. Optimizations have led to use them at $2 \mathrm{O}^{\circ} \mathrm{C}$. However, experiments with two durations (164 and $858 \mathrm{~h}$ ) were carried out under socalled "damaged conditions", i.e. at $32{ }^{\circ} \mathrm{C}$, temperature for which the ion-exchange resins efficiency was indeed lower.

\section{II.3. SEM experiments}

Two Scanning Electron Microscopes (SEM) have been used: a LEO 1450VP equipped with an Energy Dispersive X-ray analysis system (EDX), and a Karl Zeiss 1525 equipped with a field emission gun (FEG).

\section{II.4. TEM experiments}

Transmission Electron Microscopy (TEM) characterizations have been made on cross-section specimens. Before preparation, the sample was about $1 \mathrm{~cm} 2$. Two bars of about $2.5 \mathrm{~mm}$ wide were cut along the plane of interest. Both bars were glued together with an epoxy resin, the surface of the oxide layers facing inwards so that it was protected from any damage, forming a sandwich, which was then cut again into slices of $0.5 \mathrm{~mm}$ thick. A slice was first mechanically thinned to about $10 \mu \mathrm{m}$ of thickness using a precision tripod device in order to keep the sample absolutely horizontal. The sample was then mounted onto a copper grid and thinned again to a thickness of a few nanometers from both sides by low-angle $\left( \pm 7^{\circ}\right)$ ion milling with 
$4 \mathrm{keV}$ argon ions using Gatan(C) Precision Ion Polishing System (PIPS). Final milling was performed at reduced beam energy $(2 \mathrm{keV})$ and at reduced incident angles $\left( \pm 4^{\circ}\right)$ to remove most of the visible ion damage.

TEM investigations have been carried out on a Tecnai F20-ST field emission gun microscope, equipped with an Energy Dispersive X-ray (EDX) device, Gatan Imaging Filter (GIF) and owning Scanning Transmission Electron Microscopy (STEM) capabilities. STEM has been combined to High-Angle Annular Dark-Field (HAADF) technique to produce chemical contrast images formed using electrons diffracted at high angle (>40 mrad) and whose the intensity is proportional to the $Z$ atomic number of elements composing the sample. The spatial resolution of these images depends on the probe size, which was about $1 \mathrm{~nm}$ in our experiments. EDX analysis has been performed using line-scan mode to investigate local chemical composition variation over oxide layers. High-Resolution Transmission Electron Microscopy (HRTEM) images have been obtained on CCD camera and analyzed using Fast Fourier Transform (FFT) technique to investigate crystallographic details of oxide layers.

\section{Results}

Following paragraphs present results of SEM and advanced TEM investigations (HRTEM, HAADF, EDX) carried out on $\mathrm{Ni}-30 \mathrm{Cr}$ alloy and on Alloy 690 exposed for different times to a PWR simulated primary water.

\section{III.1. SEM observations}

The time evolution of the morphology of the external layer formed on Alloy 690 exposed to a PWR type primary water, for the optimal working conditions of the ion-exchange resins, is presented in Figure 2a-c. After $66 \mathrm{~h}$ exposition to the media, the surface appears clean. For exposition times from 190 to $406 \mathrm{~h}$, small crystallites are detected, but even if their number and size increase with exposition time, their presence in the working conditions of the recirculation loop keeps sporadic. EDX measures show that these crystallites are consistent with iron and nickel oxides.

On the contrary, for the two corrosion tests carried out under "damaged conditions" of the ion-exchange resins, the number and size of crystallites on the surface are much higher: the surface states at similar exposition time for both conditions are shown in Figure $2 b$ and $d$. These results underline the link existing between the amount of nickel and iron cations in the test media and the formation of the external layer. Moreover, Figure $2 \mathrm{~d}$ and e evidence a link between the crystallographic orientation of the alloy grains and the nucleation and growth of the crystallites. The growth difference of the crystallites formed on two different grains of the substrate is indeed clearly established (Figure 2e). Observation of the surface of the $\mathrm{Ni}-3 \mathrm{OCr}$ alloy (Figure 2f) leads to the same comment: crystallites are also present on the surface for long exposition times and under "damaged conditions", which reveals that the crystallites may form by precipitation of the cations contained in the media $(\mathrm{Ni}-30 \mathrm{Cr}$ alloy is almost free of iron). It also shows that the crystallites preferentially nucleate along polishing rays on the surface, thus evidencing the influence of substrate surface defects on their nucleation.

\section{III.2. TEM observations}

\section{III.2.1. Ni-3oCr alloy}

III.2.1.1. $66 \mathrm{~h}$ corrosion test

Figure 3a shows a HRTEM micrograph obtained on a cross-sectional specimen prepared from the $\mathrm{Ni}-30 \mathrm{Cr}$ alloy exposed $66 \mathrm{~h}$ in simulated primary water. The oxide layer can be distinguished between the residual glue particles and the underlying metal. It seems to form a continuous thin layer with an average thickness of $5 \mathrm{~nm}$. It is worth noting that the measure of thickness on TEM images must be done keeping in mind that the image observed in the TEM is a projection of the specimen volume. This involves the superposition of microstructural characteristics in the projected image. This effect is all the more problematic as the sample is thick and the microstructure is changing along the viewing direction. In our case, we considered that the analyzed areas are thin enough allowing to neglect this effect. 

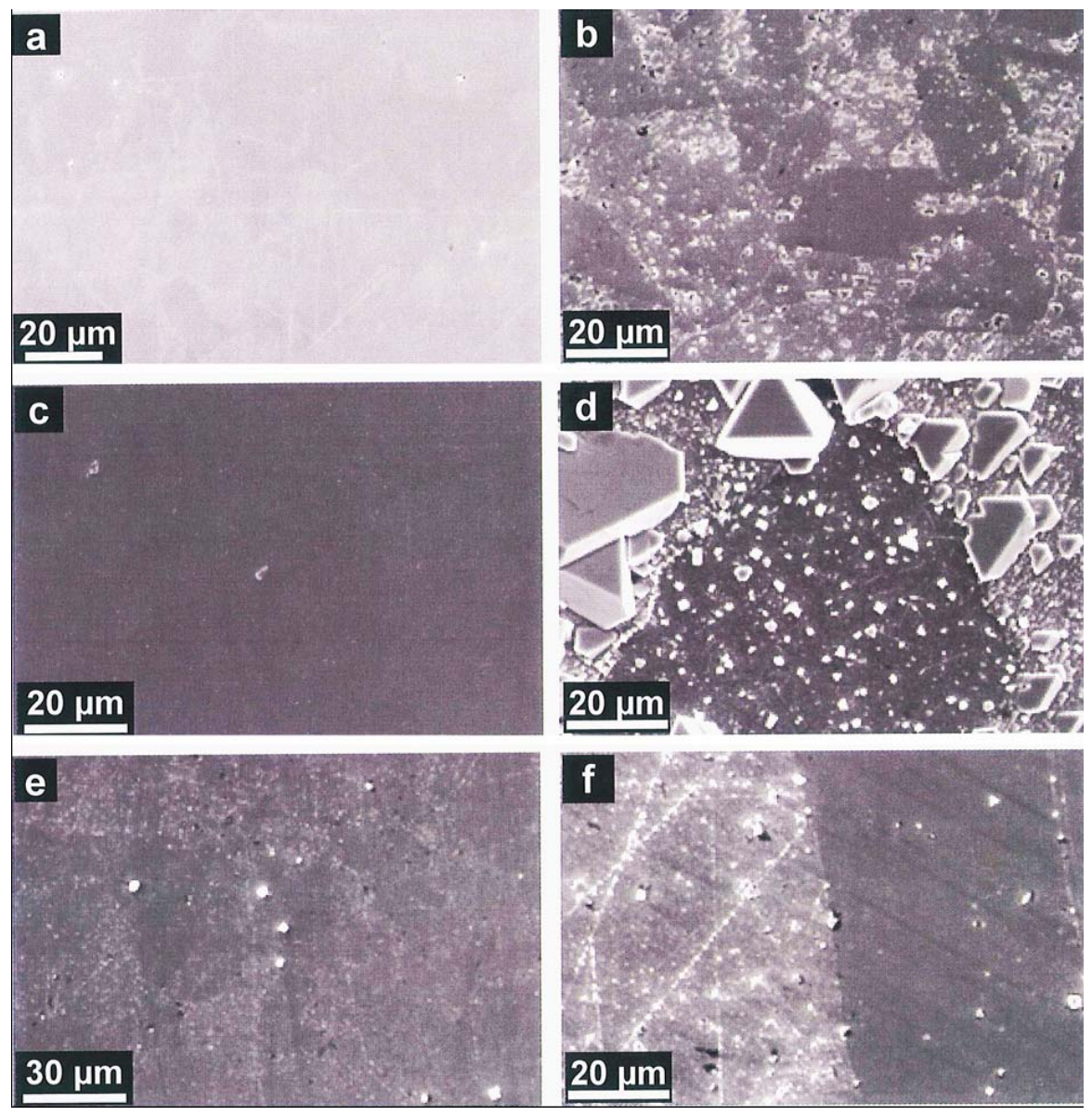

Figure 2: SEM observations of the surface of Ni-base alloys at different exposure times and for different working conditions: $(a-c)$ Alloy 690 exposed to primary water at optimized working conditions of the ion-exchange resins, for $66 \mathrm{~h} \mathrm{(a),190} \mathrm{h} \mathrm{(b)} \mathrm{and} 406 \mathrm{~h}$ (c); (d) surface of Alloy 690 after $164 \mathrm{~h}$ in PWR simulated water with damaged conditions for the ion-exchange resins; (e) zoom in of the surface of Alloy 690 after $858 \mathrm{~h}$ in damaged conditions showing preferential crystallization and big crystallites; and (f) surface of $\mathrm{Ni}-30 \mathrm{Cr}$ alloy obtained after $858 \mathrm{~h}$ in damaged conditions.

In addition to the thin layer oxide, small nodules with size ranging between 5 and $10 \mathrm{~nm}$ have been regularly observed along the oxide/alloy interface. Analysis of local areas FFT diffractograms (Figure 3b) allowed to identify them as $\mathrm{Cr}_{2} \mathrm{O}_{3}$-structure oxides owning orientation relationship with respect to the neighboring matrix of the type:

$$
\begin{aligned}
& (\overline{2} 116)_{\mathrm{Cr}_{2} \mathrm{O}_{3}} / /(200)_{\text {Matrix }} \\
& {[2 \overline{2} 01]_{\mathrm{Cr}_{2} \mathrm{O}_{3}} / /[001]_{\text {Matrix }}}
\end{aligned}
$$

\section{III.2.1.2. $164 \mathrm{~h}$ corrosion test}

Figure $3 \mathrm{c}$ shows a HRTEM image of the oxide layer developed on $\mathrm{Ni}-3 \mathrm{OCr}$ alloy exposed $164 \mathrm{~h}$. One can observe the finely grained aspect of the oxide external part where the internal part seems to be rather compact. Analysis of the rings-type FFT diffractogram (inset image) corresponding to the external oxide layer revealed atomic distance, which are in agreement with a partially hydrated nickel hydroxide, typically $\mathrm{Ni}(\mathrm{OH})_{2} \mathrm{O} .75 \mathrm{H}_{2} \mathrm{O}$.

Using a nanometric probe size, line-scan EDX analyses were realized across the oxide scale and the underlying metal. Compositional profiles are plotted in Figure $3 \mathrm{~d}$. It is worth noting that element concentrations should be regarded as qualitative since only approximate corrections were applied for $\mathrm{O}-\mathrm{Cr}$ interference and oxygen $\mathrm{X}$-ray absorption. Concentration profiles reveal that the external oxide layer is rich in nickel, which is in agreement with a nickel hydroxide owing it is impossible to detect hydrogen to confirm the $\mathrm{Ni}(\mathrm{OH})_{2} \mathrm{O} .75 \mathrm{H}_{2} \mathrm{O}$ stochiometry. However, the internal part of the oxide is rather $\mathrm{Cr}$ enriched, which may be 
Journal of Nuclear Materials, 2010, 402(2-3), 147-156, doi:10.1016/j.jnucmat.2010.05.010.

attributed to a nickel chromite $\left(\mathrm{Ni}_{(1-x)} \mathrm{Cr}_{(2+x)} \mathrm{O}_{4}\right)$. On the other hand, local EDX analysis carried out on oxide penetrations revealed a high $\mathrm{Cr}$ content with element concentrations in agreement with $\mathrm{Cr}_{2} \mathrm{O}_{3}$ composition, which may be linked to the $\mathrm{Cr}_{2} \mathrm{O}_{3}$-structure nodules previously observed along the oxide/alloy interface in the specimen exposed $66 \mathrm{~h}$. Finally, no chromium depletion zone below the oxide scale was established.
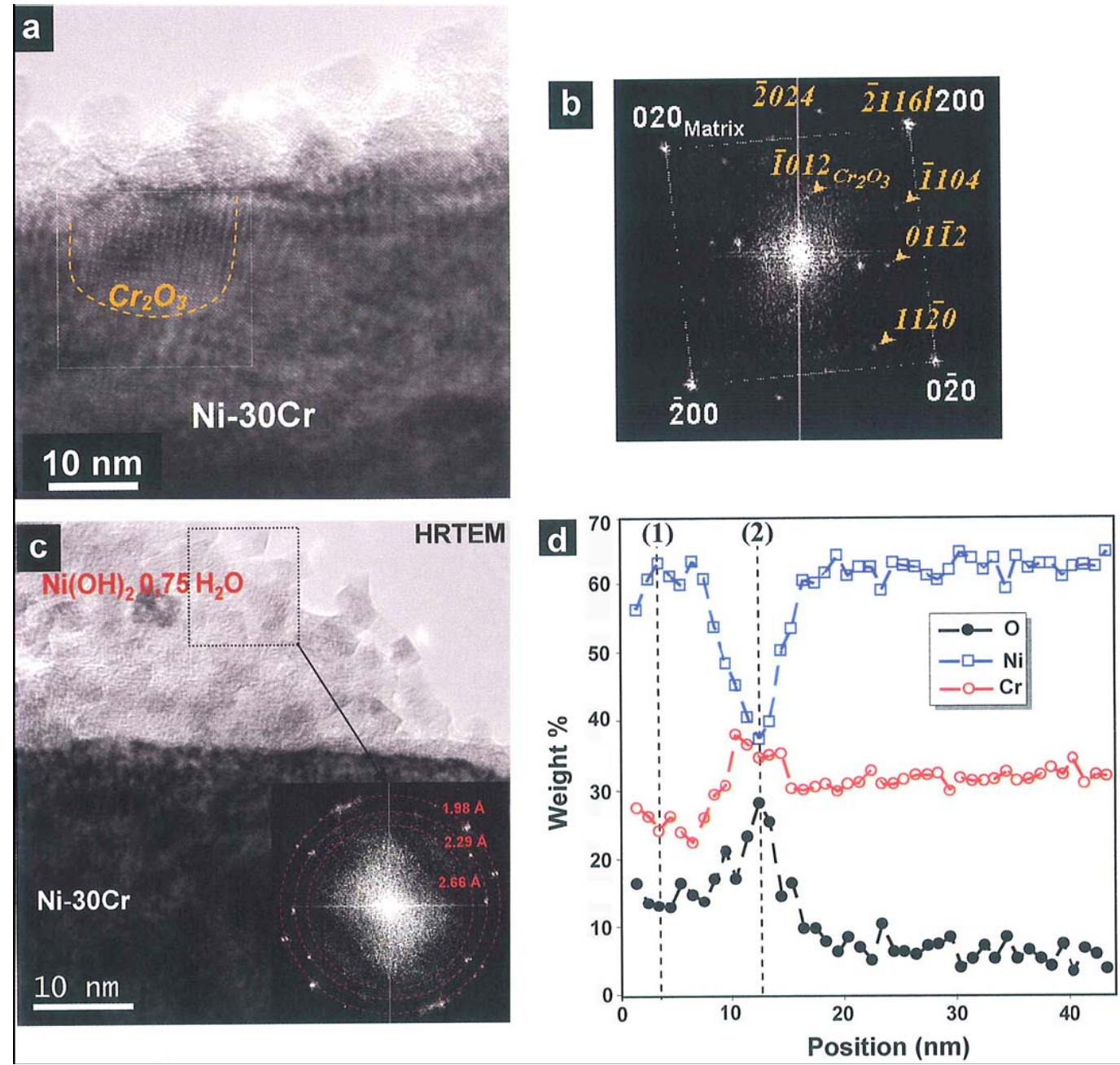

Figure 3: (a) HRTEM image of the oxide layer developed on Ni-3oCr alloy exposed $66 \mathrm{~h}$ in PWR simulated primary water. Presence of crystalline nodules at the metal/oxide interface is evidenced (dashed-lines). (b) Fourier transform diffractogram of the framed area on image (a). Nodules are clearly identified as $\mathrm{Cr}_{2} \mathrm{O}_{3}$ structure oxides. (c) HRTEM image obtained on the oxide layer developed on $\mathrm{Ni}-3 \mathrm{OCr}$ alloy exposed $164 \mathrm{~h}$ showing the granular aspect of the oxide layer. The analysis of a local area (framed zone) Fourier transform diffractogram (inset image) is in agreement with a hydrated nickel hydroxide $\left\{\mathrm{Ni}(\mathrm{OH})_{2}, \mathrm{O}_{75} \mathrm{H}_{2} \mathrm{O}\right\}$. (d) $\mathrm{EDX}$ compositional profiles obtained across the oxide layer and the underlying metal using min probe size (the atomic compositions are given at the points marked (1): $42 \% \mathrm{Ni}, 18 \% \mathrm{Cr}$ and $40 \% \mathrm{O}$ and (2): $16 \% \mathrm{Ni}, 23 \% \mathrm{Cr}$ and $61 \% 0)$.

III.2.1.3. $858 \mathrm{~h}$ corrosion test

TEM investigations carried out on the specimen exposed $858 \mathrm{~h}$ revealed a duplex oxide scale. The external layer is composed of scattered large particles with sizes varying from few tens to several hundred of nanometers (Figure 4a). Conversely, the internal layer exhibits a rather compact and continuous aspect with a quite constant thickness around $20 \mathrm{~nm}$. Furthermore, occasional penetrations of oxide in the matrix were observed (black arrow).

Crystallographic characteristics of both layers were investigated via exploitation of HRTEM images local area FFT diffractograms (Figure 4b). The image was obtained along the [1], [2], [3], [4], [5], [6], [7], [8], [9] and [10] matrix zone axis on the oxide/matrix interface. The analysis of the corresponding FFT diffractogram (inset image) highlighted the $\mathrm{NiCr}_{2} \mathrm{O}_{4}-$ structure of the internal oxide layer and established parallel orientation relationships with 
respect to the alloy. In the same manner, external large oxide particles were identified as spinel $\mathrm{NiFe}_{2} \mathrm{O}_{4}$-structure oxides (Figure 4c). However, it was not possible to establish orientation relationship between both internal and external oxide layers.
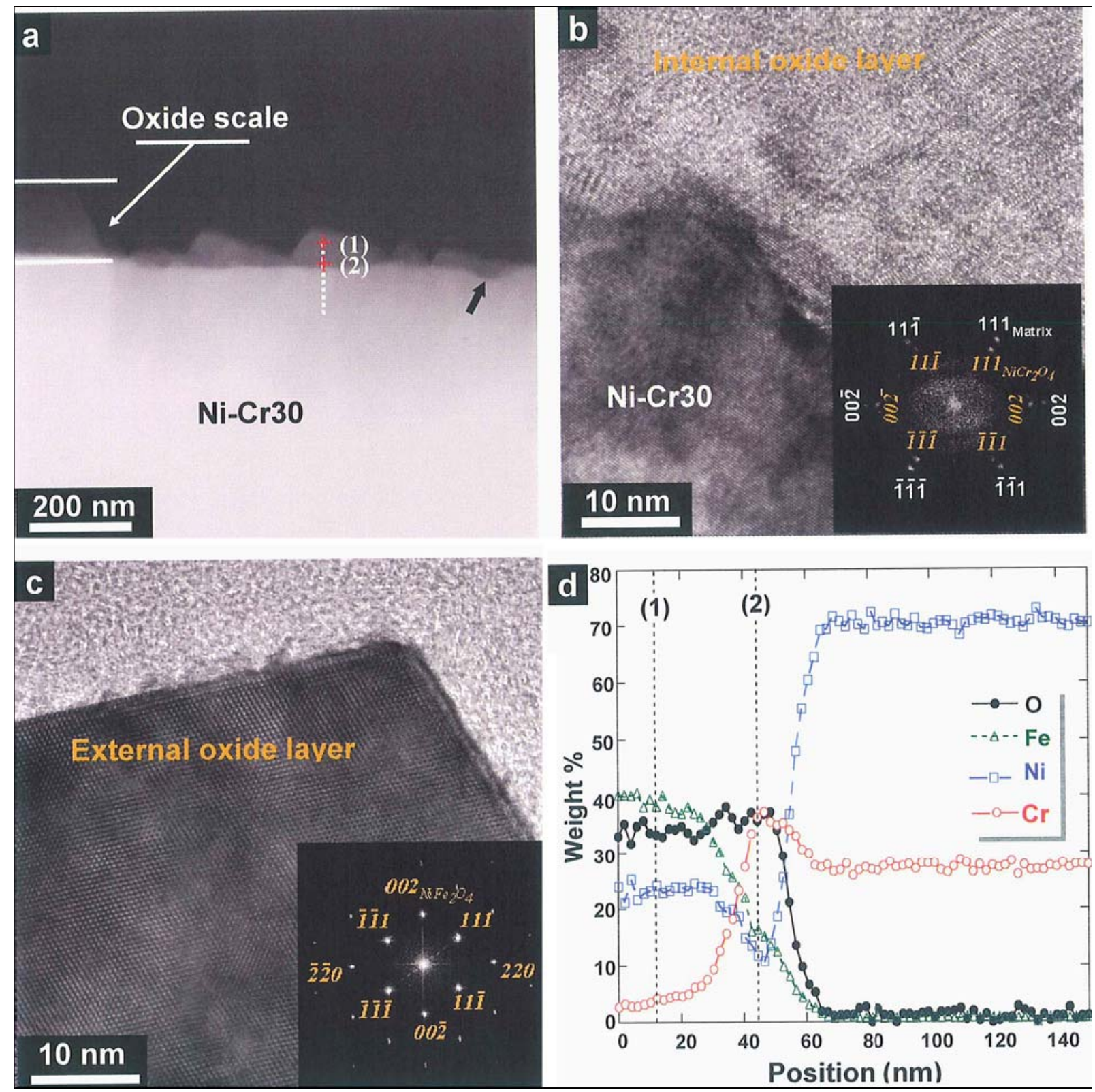

Figure 4: STEM-HAADF (a) and HRTEM (b and c) images of the oxide layer developed on Ni-3oCr alloy exposed $858 \mathrm{~h}$ showing the large crystallites forming the external oxide layer and the underlying continuous and compact internal layer. Oxide penetrations are also visible (black arrow in 4a). Fourier transform diffractograms analysis established the $\mathrm{NiCr}_{2} \mathrm{O}_{4}$-structure of the internal layer in parallel orientation with the metal (inset in 4b) and the $\mathrm{NiFe}_{2} \mathrm{O}_{4}$-structure of the large external crystallites (inset in 4c). (d) EDX compositional profiles taken using a nanometric electron probe across the oxide layer as illustrated in $4 a$ (the atomic compositions are given at the points marked (1): $23 \% \mathrm{Fe}, 12 \% \mathrm{Ni}, 1 \% \mathrm{Cr}, 64 \% \mathrm{O}$ and (2): $8 \% \mathrm{Fe}, 4 \% \mathrm{Ni}$, $22 \% \mathrm{Cr}, 66 \% \mathrm{O}$ ). Fe certainly comes from the dissolution of the autoclave metal and diffuses in the oxide layer from the simulated primary water.

The EDX compositional profiles performed along oxide scale highlighted the $\mathrm{Ni}_{(1-z)} \mathrm{Fe}_{(2+z)} \mathrm{O}_{4}$ composition, very close to $\mathrm{NiFe}_{2} \mathrm{O}_{4}$, of the outer large crystallites (Figure 4d) and where the presence of a small amount of chromium is not excluded. The internal layer is $\mathrm{Cr}$ enriched and exhibits a $\mathrm{Fe}$ concentration gradient. Atomic concentrations are in agreement with an iron and nickel mixed chromite $\left(\mathrm{Ni}_{(1-x)} \mathrm{Fe}_{x} \mathrm{Cr}_{2} \mathrm{O}_{4}\right)$. The presence of iron in the oxide layer is interesting since it is absent in the as-processed material composition. It certainly results 
Journal of Nuclear Materials, 2010, 402(2-3), 147-156, doi:10.1016/j.jnucmat.2010.05.010.

from the dissolution of the autoclave itself, and from diffusion of iron cations through the compact oxide scale from the simulated primary water to the alloy/oxide interface. Finally, one can note the absence of chromium depletion zone under the oxide scale.

III.2.2. Alloy 690

III.2.2.1. $66 \mathrm{~h}$ corrosion test

Figure 5a shows STEM-HAADF images of the oxide film developed on Alloy 690 exposed $66 \mathrm{~h}$. Although the oxide scale is very thin, deep insights on images allow to distinguish its duplex structure. The external layer is composed of fine crystallites of about $10 \mathrm{~nm}$ average size. The internal layer is rather compact and continuous with approximately $5 \mathrm{~nm}$ average thickness. Occasional oxide penetrations in the matrix were also observed conferring a rough aspect to the oxide/matrix interface.

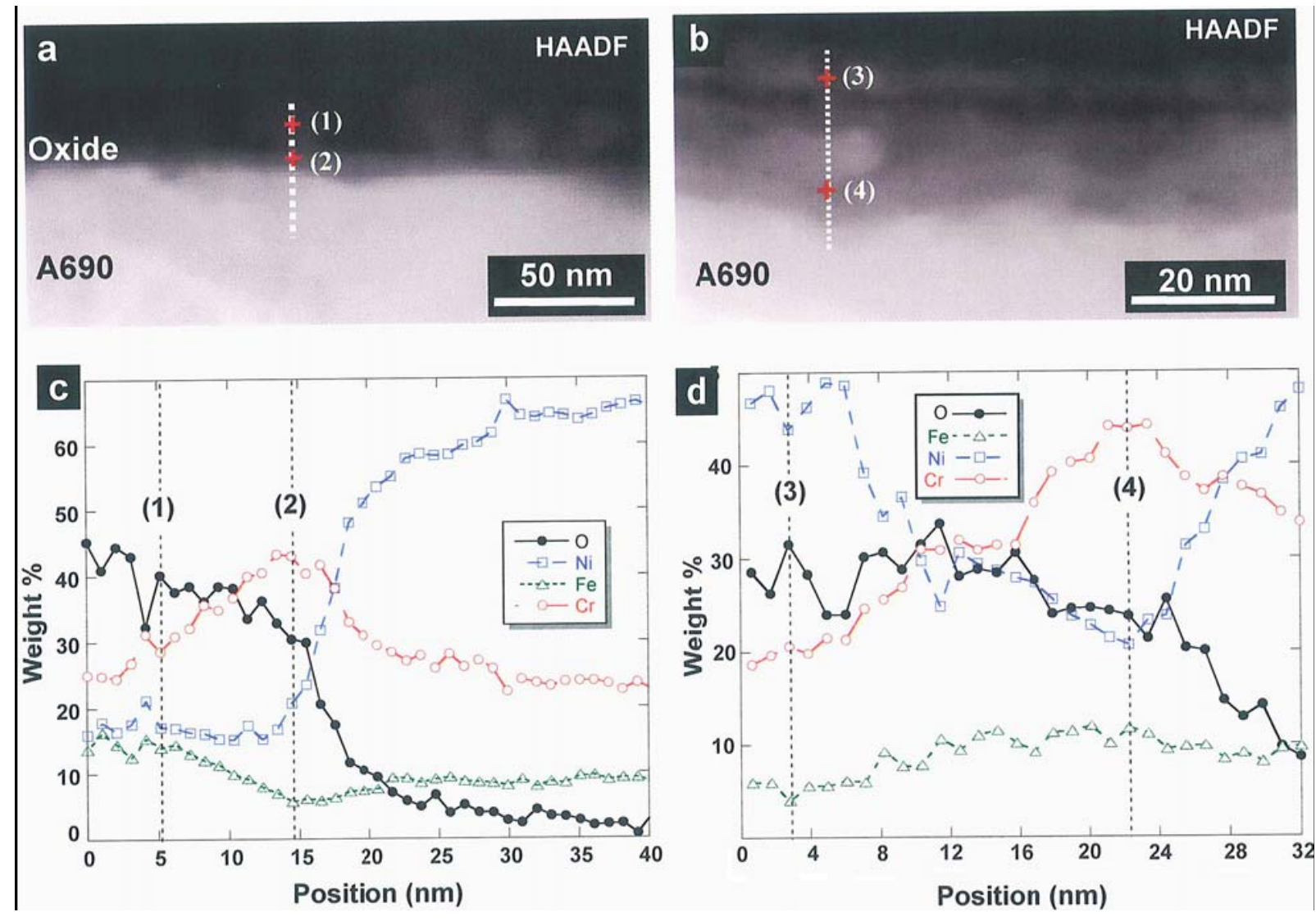

Figure 5: (a) and (b) STEM-HAADF images obtained on the oxide layer developed on Alloy 690 exposed $66 \mathrm{~h}$ and $112 \mathrm{~h}$, respectively in PWR simulated primary water; (c) EDX compositional profiles revealing the slight Feenrichment of the outer crystallites and Cr-enrichment of the inner continuous layer (the atomic compositions are given at the points marked (1): $8 \% \mathrm{Fe}, 12 \% \mathrm{Ni}, 18 \% \mathrm{Cr}$ and $62 \% \mathrm{O}$ and (2): $3 \% \mathrm{Fe}, 12 \% \mathrm{Ni}, 26 \% \mathrm{Cr}, 59 \% \mathrm{O}$ ); and (d) EDX compositional profiles indicating a Ni-enrichment of the outer part of the oxide scale and Cr-enrichment of the inner part with atomic concentrations in agreement with $\mathrm{Ni}_{(1-\mathrm{x})} \mathrm{Fe}_{\mathrm{x}} \mathrm{Cr}_{2} \mathrm{O}_{4}$ composition (the atomic compositions are given at the points marked (3): $4 \% \mathrm{Fe}, 27 \% \mathrm{Ni}, 13 \% \mathrm{Cr}$ and $56 \% \mathrm{O}$ and (4): $7 \% \mathrm{Fe}, 14 \% \mathrm{Ni}, 31 \% \mathrm{Cr}$ and $48 \% O$ ).

EDX compositional profiles realized across the oxide layer are presented in Figure 5c. Concerning the fine external crystallites, element atomic concentrations are in agreement with a mixed iron and nickel chromite $\left(\mathrm{Ni}_{(1-x)} \mathrm{Fe}_{x} \mathrm{Cr}_{2} \mathrm{O}_{4}\right)$ while the internal compact layer is rather enriched in Cr. Furthermore, oxide penetrations were particularly rich in $\mathrm{Cr}$ (50 wt.\%) and would be of $\mathrm{Cr}_{2} \mathrm{O}_{3}$ composition as it was established in the case of $\mathrm{Ni}-30 \mathrm{Cr}$ alloy (see Section III.2.1.1.).

III.2.2.2. $112 \mathrm{~h}$ corrosion test

The oxide scale developed on Alloy 690 exposed $112 \mathrm{~h}$ is shown in Figure 5b. It seems composed of two superimposed layers. The outer one consists in a thin and granular layer of 
about $10 \mathrm{~nm}$ average thickness. The inner layer, whose average thickness is about $15 \mathrm{~nm}$, exhibits a rather compact structure with occasional oxide penetrations in the alloy.

EDX line-scan analyses were realized across the oxide scale and the obtained composition profiles are plotted in Figure $5 \mathrm{~d}$. They reveal a Ni-enrichment of the external oxide layer similar to the case of $\mathrm{Ni}-30 \mathrm{Cr}$ alloy corroded $164 \mathrm{~h}$, which may indicate a formation of a nickel hydroxide. The internal layer is rather chromium enriched with atomic concentrations in agreement with a mixed iron and nickel chromite $\left(\mathrm{Ni}_{(1-x)} \mathrm{Fe}_{x} \mathrm{Cr}_{2} \mathrm{O}_{4}\right)$.

III.2.2.3. $858 \mathrm{~h}$ corrosion test

TEM micrographs obtained on the oxide film developed on Alloy 690 exposed $858 \mathrm{~h}$ are shown on Figure $6 \mathrm{a}-\mathrm{d}$. As in the case of $\mathrm{Ni}-30 \mathrm{Cr}$ alloy, the duplex structure is clearly visible. The external oxide layer is composed of scattered crystallites, which can be divided into two families: large crystallites with sizes greater than $100 \mathrm{~nm}$ and small crystallites with sizes not exceeding few tens of nanometers (Figure 6a). The internal layer exhibits a more continuous and compact aspect with a roughly constant thickness around $60 \mathrm{~nm}$. Deep insight on the oxide/matrix interface (Figure 6b) highlights the presence of small nodules distributed along the interface (white arrow).

Figure $6 \mathrm{c}$ shows a HRTEM image obtained at the interface between the external and the internal oxide layers. The indexation of the corresponding FFT diffractogram (see inset) established the spinel $\mathrm{NiCr}_{2} \mathrm{O}_{4}$ and $\mathrm{NiFe}_{2} \mathrm{O}_{4}$ structures of the internal and the external layers, respectively. Moreover, an orientation relationship between both oxide layers was established:

$$
\begin{aligned}
& (111)_{\mathrm{NiFe}_{2} \mathrm{O}_{4}} / /(101)_{\mathrm{NiCr}_{2} \mathrm{O}_{4}} \\
& {[110]_{\mathrm{NiFe}_{2} \mathrm{O}_{4}} / /[010]_{\mathrm{NiCr}_{2} \mathrm{O}_{4}}}
\end{aligned}
$$

Figure $6 \mathrm{~d}$ highlights the inner interface between the oxide scale and the alloy showing a $\mathrm{Cr}_{2} \mathrm{O}_{3}$ nodule and evidences the epitaxy relationships (see inset) between the $\mathrm{NiCr}_{2} \mathrm{O}_{4}$-structure internal layer and the metal as:

$$
\begin{aligned}
& (111)_{\mathrm{NiCr}_{2} \mathrm{O}_{4}} / /(111)_{\mathrm{A} 690} \\
& {[011]_{\mathrm{NiCr}_{2} \mathrm{O}_{4}} / /[011]_{\mathrm{A} 690}}
\end{aligned}
$$

EDX chemical analysis made across the oxide scale of Figure 6e confirmed the chromium enrichment (43 wt.\%) of the internal layer, with element concentrations in agreement with a mixed iron and nickel chromite $\left(\mathrm{Ni}_{(1-x)} \mathrm{Fe}_{x} \mathrm{Cr}_{2} \mathrm{O}_{4}\right)$ (Figure 6f). Furthermore, and as expected, the large external crystallites are Fe-enriched, with element concentrations in agreement with $\left(\mathrm{Ni}_{(1-z)} \mathrm{Fe}_{(2+z)} \mathrm{O}_{4}\right)$ composition. Finally, the concentration profiles did not reveal any $\mathrm{Cr}-$ depleted zone below the oxide scale.

\section{Discussion}

\section{IV.1. Thermodynamic considerations}

The experimental TEM study has pointed out the different phases, which can be formed during the oxidation of Ni-base alloys in PWR primary conditions. These results can be compared with the ones obtained by the thermodynamic calculations on the oxides stability in identical conditions. The thermodynamic work were performed on the $\mathrm{Ni}-\mathrm{Cr}-\mathrm{Fe}-\mathrm{H}_{2} \mathrm{O}-\mathrm{H}_{2}$ system and applied to the case of Alloy 690. Several assumptions are needed in order to perform the calculation.

- The alloy is supposed to be an ideal solid solution in which the activity of each constituent is equal to its molar fraction. The oxides are supposed to be pure in their phase. Their activity is equal to 1 . The variation of their standard chemical potential with the temperature is calculated based on data of Knacke et al. [15]. It is supposed that these chemical potentials are independent of pressure. 

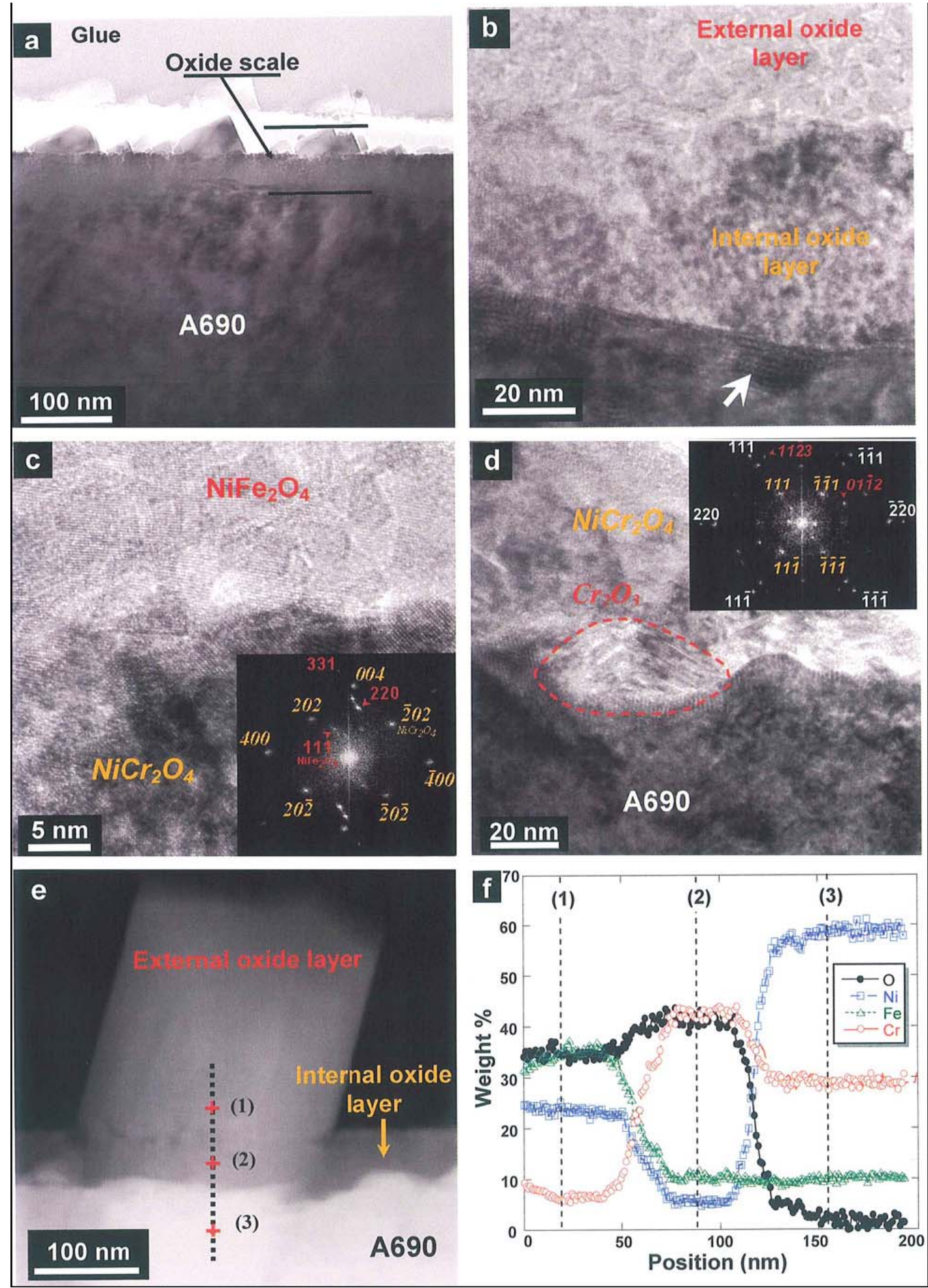

Figure 6: TEM (a) and HRTEM ( $b$ and c) images of the oxide layer developed on Alloy 690 exposed $858 \mathrm{~h}$ showing the large crystallites forming the external oxide layer and the continuous and compact internal layer. Analysis of image FFT diffractograms (inset in $6 \mathrm{c}$ ) established the $\mathrm{NiCr}_{2} \mathrm{O}_{4}$-structure of the internal layer and the $\mathrm{NiFe}_{2} \mathrm{O}_{4}$-structure of the large crystallites with orientation relationships between both layers; (d) HRTEM image and corresponding FFT diffractogram showing epitaxy between $\mathrm{Cr}_{2} \mathrm{O}_{3}$-structure nodules (dashed-line delimited zone) and spinal $\mathrm{NiCr}_{2} \mathrm{O}_{4}$-structure internal layer at the oxide/alloy interface. (e) HAADF image of the crosssection of the oxide scale developed on Alloy 690 exposed $858 \mathrm{~h}$; and $(f)$ EDX compositional profiles across the oxide layer and the alloy as illustrated in (e) (the atomic compositions are given at the points marked (1): 19\%Fe, $11 \% \mathrm{Ni}, 4 \% \mathrm{Cr}, 65 \% \mathrm{O}$, (2): $5 \% \mathrm{Fe}, 3 \% \mathrm{Ni}, 22 \% \mathrm{Cr}, 70 \% \mathrm{O}$ and (3): $10 \% \mathrm{Fe}, 58 \% \mathrm{Ni}, 32 \% \mathrm{Cr}$ ). 
* The standard chemical potential of aqueous species in high temperature aqueous water is supposed to depend of pressure, as proposed by Shock et al. [16], [17] and [18] in the HKF (Helgeson-Kirkham-Flowers) revised model. The standard chemical potential of liquid water is calculated as a function of temperature and pressure from IAPWS (International Association for the Properties of Water and Steam) formulation [19]. For each temperature, the pressure is the one corresponding to the liquid-vapor equilibrium. The standard chemical potential of dissolved hydrogen in aqueous solution is calculated as a function of temperature and pressure from the revised HKF model [16], [17] and [18].

The oxidation reaction of a binary alloy (A and B) with aqueous water at high temperature can be written as:

$$
a\langle\langle A\rangle\rangle+b\langle\langle B\rangle\rangle+c \mathrm{H}_{2} \mathrm{O} \rightleftarrows \mathrm{A}_{a} \mathrm{~B}_{b} \mathrm{O}_{c}+c \mathrm{H}_{2(a q)}
$$

The reaction Gibbs energy associated to this reaction at a temperature $T$ and a pressure $P$ is given by:

$$
\Delta G(T, P)=\Delta G^{0}(T, P)+R T \ln \frac{a_{H_{2}^{(a q)}}^{c}}{a_{\langle\langle A\rangle\rangle}^{a} a_{\langle\langle B\rangle\rangle}^{b} a_{H_{2} \mathrm{O}}^{c}}
$$

where $\Delta G^{\circ}(T, P)$ is the standard reaction Gibbs energy, $R$ is the ideal gas constant, $a_{H_{2}^{(a q)}}$ is the dissolved hydrogen activity, $a_{\langle\langle A\rangle\rangle}$ is the activity of the metal $\mathrm{A}$ in the alloy, $a_{\langle\langle B\rangle\rangle}$ is the activity of the metal $\mathrm{B}$ in the alloy, $a_{\mathrm{H}_{2} \mathrm{O}}$ is the water activity and $a, b, c$ are the stochiometric coefficients of reaction. Then, it is possible to calculate the water activity on hydrogen activity ratio, which can be considered as an oxidizing potential:

$$
\frac{a_{H_{2}^{0}}}{a_{H_{2}^{(a q)}}}=\left(a_{\langle\langle A\rangle\rangle}^{a} a_{\langle\langle B\rangle\rangle}^{b} e-\frac{\Delta G_{0}(T, P)}{R T}\right)-\frac{1}{c}
$$

It has to be noted that the Equations (4) (5) and (6) are also helpful for the calculation of the oxidizing potential of a sole metal A by considering $b$ equal to 0 .

The oxidation reactions, which were taken into account for the thermodynamic calculations, are the following ones:

$$
\begin{aligned}
& \langle\langle\mathrm{Ni}\rangle\rangle+\mathrm{H}_{2} \mathrm{O} \rightleftarrows \mathrm{NiO}+\mathrm{H}_{2(a q)} \\
& \langle\langle\mathrm{Cr}\rangle\rangle+3 \mathrm{H}_{2} \mathrm{O} \rightleftarrows \mathrm{Cr}_{2} \mathrm{O}_{3}+3 \mathrm{H}_{2(a q)} \\
& \langle\langle\mathrm{Ni}\rangle\rangle+2\langle\langle\mathrm{Cr}\rangle\rangle+4 \mathrm{H}_{2} \mathrm{O} \rightleftarrows \mathrm{NiCr}_{2} \mathrm{O}_{4}+4 \mathrm{H}_{2(a q)} \\
& \langle\langle\mathrm{Fe}\rangle\rangle+2\langle\langle\mathrm{Cr}\rangle\rangle+4 \mathrm{H}_{2} \mathrm{O} \rightleftarrows \mathrm{FeCr}_{2} \mathrm{O}_{4}+4 \mathrm{H}_{2(a q)} \\
& \langle\langle\mathrm{Ni}\rangle\rangle+2\langle\langle\mathrm{Fe}\rangle\rangle+4 \mathrm{H}_{2} \mathrm{O} \rightleftarrows \mathrm{NiFe}_{2} \mathrm{O}_{4}+4 \mathrm{H}_{2(a q)}
\end{aligned}
$$

Using the formulae and the assumptions described above, the oxidizing potential was calculated for each oxidation reaction and represented as a function of temperature on Figure $7 \mathrm{a}$ and $\mathrm{b}$, in the case of Alloy 690. In addition, the oxidizing potential (in the present experimental conditions and its upper and lower limits for PWR primary nominal conditions) was drawn on Figure 7. For this, the activity of water, this time being the solvent, was taken equal to 1 and the activity of dissolved hydrogen was taken equal to its concentration in water. This concentration was calculated from the partial pressure of hydrogen in equilibrium with 
Journal of Nuclear Materials, 2010, 402(2-3), 147-156, doi:10.1016/j.jnucmat.2010.05.010.

the aqueous phase and using the Henry constant of hydrogen, which varies in function of temperature and pressure [20].
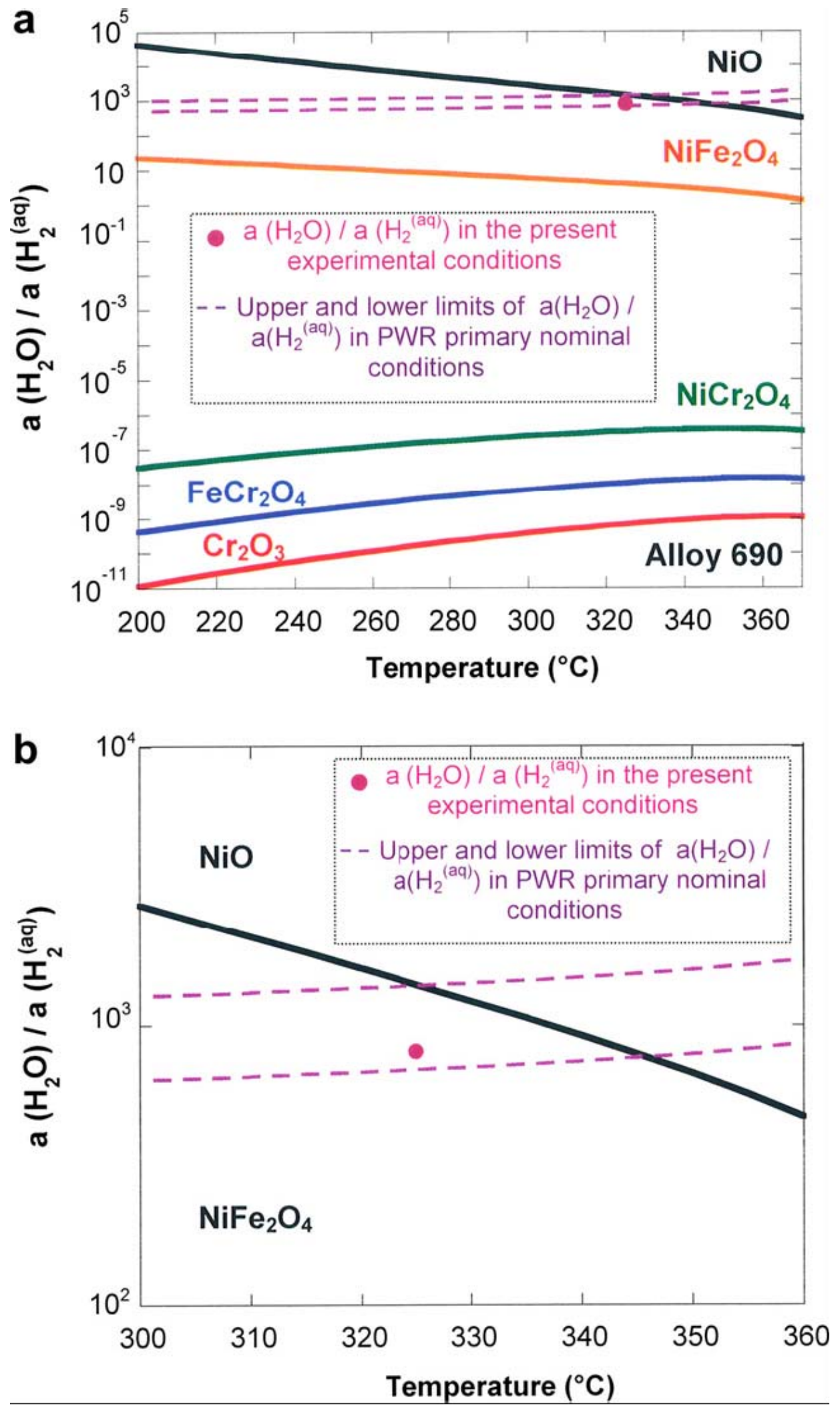

Figure 7: (a) Stability diagram of the oxides which are likely to form during the exposition of Alloy 690 in PWR primary water type media in function of temperature; and (b) an enlargement at the vicinity of the equilibrium oxidizing power for the formation of $\mathrm{NiO}$. 
Journal of Nuclear Materials, 2010, 402(2-3), 147-156, doi:10.1016/j.jnucmat.2010.05.010.

From the calculations and stability diagrams presented in Figure $7 \mathrm{a}$, a thermodynamic classification of the oxides can be extracted, rating them by decreasing stability:

$$
\mathrm{Cr}_{2} \mathrm{O}_{3}>\mathrm{FeCr}_{2} \mathrm{O}_{4}>\mathrm{NiCr}_{2} \mathrm{O}_{4}>\mathrm{NiFe}_{2} \mathrm{O}_{4}>\mathrm{NiO}
$$

It has to be noted that $\mathrm{NiO}$ is not stable in our experimental conditions (Figure $7 \mathrm{~b}$ ), which well agrees with our results. From the stability diagrams it comes also that, except NiO, all the other oxides taken into account are likely to grow during the exposition of this kind of nickelbase alloys in PWR primary water conditions.

Besides, it appears that the succession of stability domains of each oxide in function of the oxidizing power fits well the sequence of the multi-layer structure that was evidenced earlier by TEM observations. The more stable oxides were indeed situated at the inner interface $\left(\mathrm{Cr}_{2} \mathrm{O}_{3}\right.$ nodules) whereas the less stable $\left(\mathrm{Ni}_{(1-z)} \mathrm{Fe}_{(2+z)} \mathrm{O}_{4}\right.$ precipitates) were found at the outermost interface. Between these two oxides, the formation of a compact scale of iron and nickel mixed chromite is consistent with thermodynamic calculations.

Moreover, HRTEM analysis evidenced the presence of partially hydrated nickel hydroxide in the external layer, and one could question its stability. The following reaction of $\beta-\mathrm{Ni}(\mathrm{OH})_{2}$ formation can be used in order to discuss the thermodynamic stability of nickel hydroxide :

$$
\langle\langle\mathrm{Ni}\rangle\rangle+2 \mathrm{H}_{2} \mathrm{O} \rightleftarrows \beta-\mathrm{Ni}(\mathrm{OH})_{2}+\mathrm{H}_{2(a q)}
$$

Based on thermodynamic data published for $\beta-\mathrm{Ni}(\mathrm{OH})_{2}$ [21], [22] and [23] and on assumptions previously discussed, the variation of Gibbs energy for reaction (12) in our experimental conditions can be plotted as a function of temperature (Figure 8). Figure 8 shows that, in the range of temperature considered, $\beta-\mathrm{Ni}(\mathrm{OH})_{2}$ is never a stable corrosion product of the two nickel-base alloys studied. It can also be pointed out that, in our experimental conditions, the predominant aqueous form of nickel cations is the neutral aqueous complex $\mathrm{Ni}(\mathrm{OH})_{2(\text { aq })}$ [21]. The partially hydrated nickel hydroxide characterized by TEM could therefore be due to precipitation of a metastable phase.

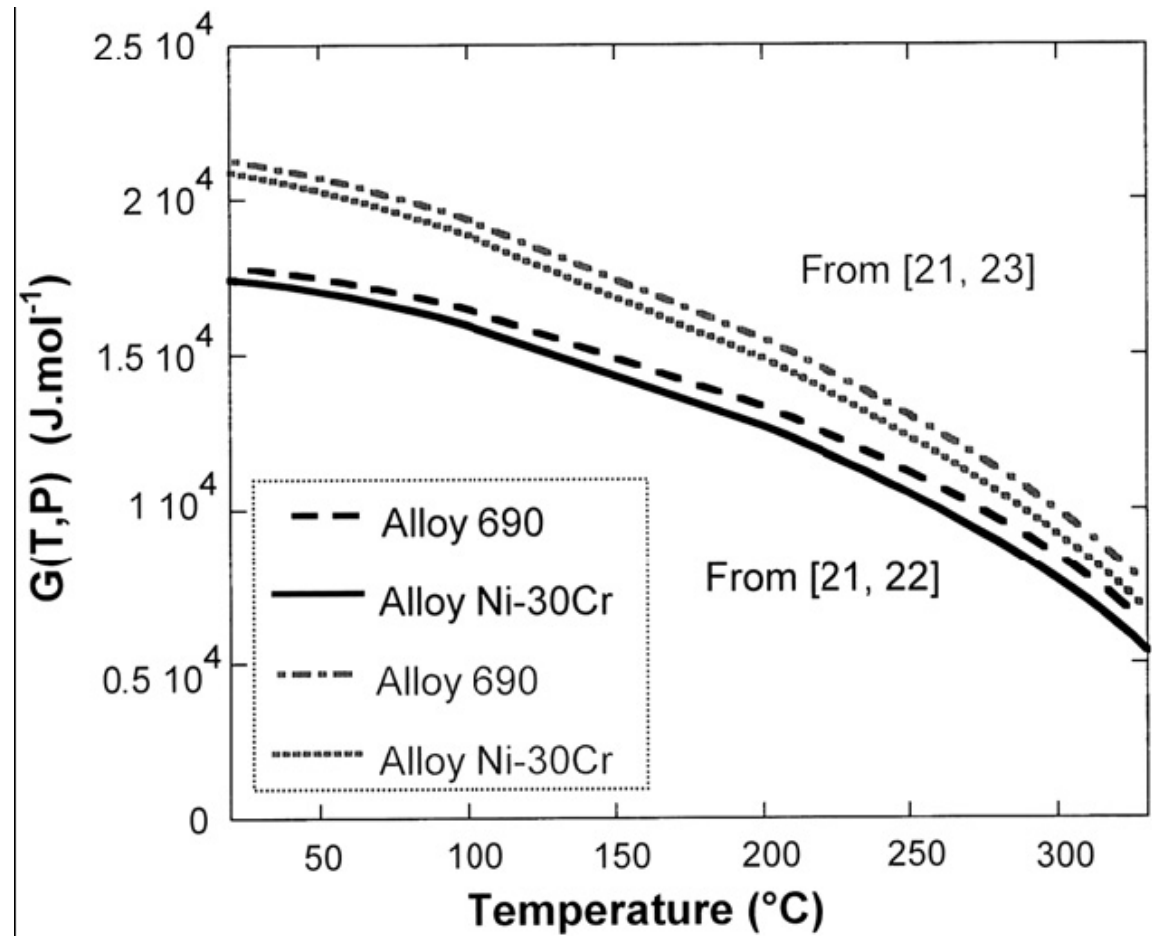

Figure 8: Evolution of free reaction enthalpy for $\beta-\mathrm{Ni}(\mathrm{OH})_{2}$ formation versus temperature for the alloys 690 and

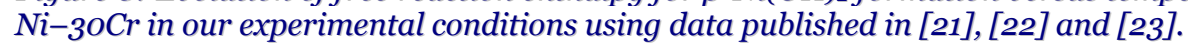


IV.2. The multilayered structure in detail

A schematic view of this multilayered structure is presented in Figure 9. This structure can be divided in two parts: an external discontinuous layer and a compact protective inner layer. The presence, formation, composition and growth of each sub-layer will now be detailed and discussed.

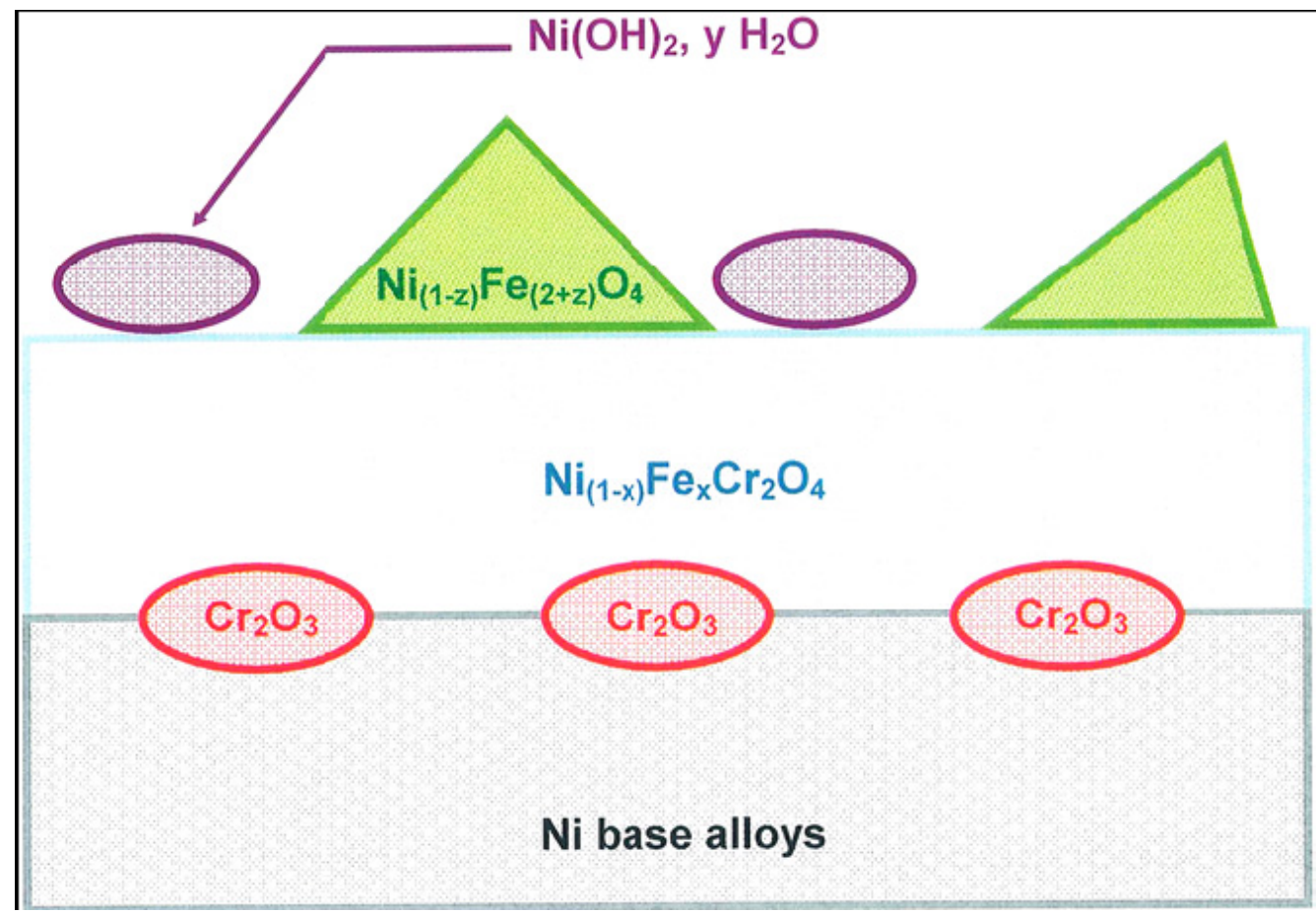

Figure 9: Schematic view of the oxide scale that forms during the exposition of Ni-base alloys in PWR primary water.

\section{IV.2.1. External layer}

The external layer is composed of nickel ferrite crystallites, whose size can reach the micrometric scale, and whose composition seems to depend on the nickel and iron concentrations present in the aqueous solution. Two observations suggest that the formation of these crystallites results, at least partially, from a precipitation phenomenon. Firstly, they form at the surface of the $\mathrm{Ni}-30 \mathrm{Cr}$ alloy, which does not contain any Fe. Second, the number of crystallites per surface unity could be drastically reduced almost until complete disappearing when the ion-exchange resins worked in optimal conditions, as showed by the SEM observation of the sample surface.

The influence of the surface defects and of the crystalline orientation of the alloy on the nucleation and/or growth of these crystallites was observed. More than that, these influences propagate across a continuous layer. This can be explained, in the case of surface defects, by the low thickness of this protective layer, which is not sufficient enough to fade the marks of the alloy initial surface. Concerning the influence of the alloy crystalline orientation, it can be explained by the existence of two successive epitaxy relationships, between the alloy and the chromite layer, then between the chromite and the ferrite crystallites (observed by TEM). These results on the nature of the crystallites and the influence of the surface state or of the concentration in iron or nickel cations on their nucleation and growth are in overall good agreement with the literature [9], [10], [12], [24] and [25].

The presence of nickel hydroxide in the external layer was identified by XPS by several authors [9], [10] and [11]. This hydroxide, partially hydrated, has also been identified in this study, in one case, by HRTEM characterizations (Figure 3c). It seems to form a discontinuous layer, constituted of globulous-looking aggregates of few $\mathrm{nm}$. The thermodynamic considerations discussed above permit to propose that the solid $\mathrm{Ni}(\mathrm{OH})_{2}, y \mathrm{H}_{2} \mathrm{O}$ exists in a metastable state in our high temperature aqueous hydrogenated media, and that its formation 
could result from the precipitation of the neutral aqueous complex $\mathrm{Ni}(\mathrm{OH})_{2(\mathrm{aq})}$. The issue about the final stable state of this precipitate is raised.

In experimental conditions close to those used in this work, Carrette [10] has observed, by XPS, the formation of iron hydroxide in the oxide layer formed on Alloy 690. In the same way than in the case of nickel hydroxide, in this type of experimental conditions, solid iron hydroxide was not stable, contrary to the neutral aqueous complex $\mathrm{Fe}(\mathrm{OH}) 2(\mathrm{aq})$, which is the stable form of iron cations in solution [26].

Based on these various data, it is suggested that the precipitation of nickel or iron hydroxides could be an intermediate step in the formation of the stable precipitate. By analogy with the Schikorr reaction used in literature to describe the growth of magnetite from iron hydroxide in the case of high temperature aqueous corrosion of stainless steels [27], or in the case of the growth of nickel ferrite [28], [29] and [30], a growth mechanism of $\mathrm{Ni}_{(1-z)} \mathrm{Fe}_{(2+z)} \mathrm{O}_{4}$ taking into account the role of metastable iron and nickel hydroxide could be proposed.

The release of $\mathrm{Fe}$ and $\mathrm{Ni}$ cations in the media may lead to local sursaturation at the vicinity of the surface of the oxidized alloy. The formation of metastable solid nickel and iron hydroxides on the surface could result from precipitation of the stable neutral aqueous complex, following reactions like:

$$
\begin{aligned}
& \mathrm{Ni}(\mathrm{OH})_{2(a q)} \rightleftarrows \mathrm{Ni}(\mathrm{OH})_{2} \\
& \mathrm{Fe}(\mathrm{OH})_{2(a q)} \rightleftarrows \mathrm{Fe}(\mathrm{OH})_{2}
\end{aligned}
$$

Once formed on the protective oxide scale, these metastable hydroxides may diffuse in surface to preferential sites, where nucleation or growth of nickel ferrite may occur:

$$
(2+\mathrm{z}) \mathrm{Fe}(\mathrm{OH})_{2}+(1-\mathrm{z}) \mathrm{Ni}(\mathrm{OH})_{2} \rightleftarrows \mathrm{Ni}_{(1-z)} \mathrm{Fe}_{(2+z)} \mathrm{O}_{4}+2 \mathrm{H}_{2} \mathrm{O}+\mathrm{H}_{2(a q)}
$$

Such a mechanism resulting from precipitation phenomena due to local sursaturation would be able to describe the influence of the concentrations of $\mathrm{Fe}$ and Ni cations in the solution on the stochiometry of nickel ferrite.

\section{IV.2.2. Internal continuous layer}

The protective part of the multilayered structure mainly consists of a compact oxide layer, whose crystallographic structure corresponds to the spinel type nickel chromite. STEM-EDX analysis have evidenced a link between the composition of this layer and the amount of iron, nickel and chromium in the medium studied, so that this oxide was described as a mixed nickel and iron chromite, whose formula can be written as: $\mathrm{Ni}_{(1-x)} \mathrm{Fe}_{x} \mathrm{Cr}_{2} \mathrm{O}_{4}$.

The presence, inside the oxide layer growing on nickel-base alloys exposed to PWR primary water conditions, of a spinel type chromite has already been suggested by many authors [6], [10] and [25]. Moreover, it was shown undoubtedly here, thanks to the TEM observations, that this spinel type chromite constitutes the only continuous layer evidenced in the framework of this study. It has to be noted that its chemical composition depends on the cations in solution in the primary simulated media. As shown in Figure 6, iron is present in the chromite spinel formed on $\mathrm{Ni}-30 \mathrm{Cr}$ alloy although this alloy is iron free.

Coupling HRTEM and STEM-EDX observations revealed also the presence of $\mathrm{Cr}_{2} \mathrm{O}_{3}$ nodules, which were almost periodically dispersed at the inner chromite/alloy interface. These results complete some literature, in which an enriched chromium continuous layer, $\operatorname{or} \mathrm{Cr}_{2} \mathrm{O}_{3}$, has been proposed [6], [10], [11] and [25]. In addition, no chromium depleted zone was ever observed across the underlying alloy close to the chromite/metal interface, contrarily to some previous works [6], [10], [11] and [25], in which a chromium depletion in the underlying alloy close to the interface has been observed. This difference can be explained by the surface defect density of the different samples, used in the different works, which could play a role on the nucleation and growth of $\mathrm{Cr}_{2} \mathrm{O}_{3}$ and consequently on the chromium depleted zone in alloy sub-surface. 


\section{Conclusions}

The multi-layer oxide structure formed during corrosion of nickel-base alloys in PWR primary simulated media has been characterized by SEM and advanced TEM techniques. The internal layer can be divided into a continuous film of $\mathrm{Ni}_{(1-x)} \mathrm{Fe}_{x} \mathrm{Cr}_{2} \mathrm{O}_{4}$, in which the content of $\mathrm{Fe}$ and $\mathrm{Ni}$ is dependent on the concentrations of $\mathrm{Fe}$ and $\mathrm{Ni}$ cations in the solution, and nodules of $\mathrm{Cr}_{2} \mathrm{O}_{3}$ dispersed at the alloy/oxide interface. The external layer is composed of a nickel ferrite and Ni hydroxide, their growth resulting from precipitation phenomena. The precipitation of $\mathrm{Ni}$ hydroxide may be an intermediate step in the nucleation and growth of $\mathrm{Ni}_{(1-z)} \mathrm{Fe}_{(2+z)} \mathrm{O}_{4}$. A mechanism, involving the formation of metastable $\mathrm{Ni}$ and Fe hydroxides, was proposed, which permits to understand the link between the concentrations of $\mathrm{Fe}$ and $\mathrm{Ni}$ cations in the media and the content of these elements in the nickel ferrite.

These results permit to propose a multi-layer structure, which gives a coherent description of the oxide scale formed on Ni-base alloys during corrosion tests carried out in this study. They also highlight divergences with other studies [6], [10], [12] and [25], notably in terms of structure of the protective oxide scale and chromium depletion in the basis material. In particular, the existence or not of a continuous $\mathrm{Cr}_{2} \mathrm{O}_{3}$ thin layer could be of great importance as far as the question of release of $\mathrm{Ni}$ and $\mathrm{Fe}$ cations from the oxide towards the primary water is concerned. In order to clarify these points, a study of the growth mechanism of protective oxide must be done and is the subject of further works.

\section{References}

[1] N.S. McIntyre, D.G. Zetaruk and D. Oven, J. Electrochem. Soc. 126 (1979), pp. 750-760.

[2] L. Guinard, O. Kerrec, D. Noel, S. Gardey and F. Coulet, Nucl. Energy 36 (1997), pp. 1927.

[3] F. Carrette, M.C. Lafont, G. Chatainier, L. Guinard and B. Pieraggi, Surf. Interface Anal. 34 (2002), pp. 135-138.

[4] F. Carrette, L. Guinard, B. Pieraggi, in: Proceedings of the International Conference on water Chemistry of Nuclear Reactor Systems, Operation Optimisation and New Developments, 2002.

[5] A. Machet, A. Galtayries, P. Marcus, P. Combrade, P. Jolivet and P. Scott, Surf. Interface Anal. 34 (2002), pp. 197-200.

[6] F. Carrette, M.C. Lafont, L. Legras, L. Guinard and B. Pieraggi, Mater. High Temp. 20 (2003), pp. 581-591.

[7] A. Machet, A. Galtayries, S. Zanna, L. Klein, V. Maurice, P. Jolivet, M. Foucault, P. Combrade, P. Scott and P. Marcus, Electrochim. Acta 49 (2004), pp. 3957-3964.

[8] F. Delabrouille, B. Viguier, L. Legras and E. Andrieu, Mater. High Temp. 22 (2005), pp. 287-292.

[9] S. Gardey, Etude de la corrosion généralisée des alliages 600, 690 et 800 en milieu primaire, Contribution à la compréhension des mécanismes, Ph.D. Thesis, University of Paris VI, 1998.

[10] F. Carrette, Relâchement des produits de corrosion des tubes en alliage 690 de générateur de vapeur du circuit primaire des réacteurs à eau pressurisée, Ph.D. Thesis, Polytechnic National Institute of Toulouse, 2002.

[11] A. Machet, Etude des premiers stades d'oxydation d'alliages inoxydables dans l'eau à haute température, Ph.D. Thesis, University of Paris VI, 2004.

[12] F. Delabrouille, Caractérisation par MET de fissures de corrosion sous contraintes d'alliages à base de nickel: influence de la teneur en chrome et de la chimie du milieu, Ph.D. Thesis, Polytechnic National Institute of Toulouse, 2004.

[13] A. Machet, A. Galtayries, S. Zanna, P. Jolivet, M. Foucault, P. Combrade, P. Scott, P. Marcus, in: Proceedings of the EUROCORR, Nice, France, 2004.

[14] J. Panter, B. Viguier, J.-M. Cloué, M. Foucault, P. Combrade and E. Andrieu, J. Nucl. Mater. 348 (2006), pp. 213-221.

[15] O. Knacke, O. Kubaschewski, K. Hesselmann (Eds.), Thermochemical Properties of Inorganic Substances, Springer-Verlag, Berlin, Germany, 1991. 
[16] J.C. Tanger and H.C. Helgeson, Am. J. Sci. 288 (1988), pp. 19-98.

[17] E.L. Shock and H.C. Helgeson, Geochim. Cosmochim. Acta 52 (1988), pp. 2009-2036.

[18] E.L. Shock, H.C. Helgeson and D.A. Sverjensky, Geochim. Cosmochim. Acta 53 (1989), pp. 2157-2183.

[19] W. Wagner, J.R. Cooper, A. Dittmann, J. Kijima, H.J. Kretzschmar, A. Kruse, R. Mareš, K. Oguchi, H. Sato, J. Stöcker, O. Sifner, Y. Takaishi, I. Tanishita, J. Trubenbach and T. Willkommen, J. Eng. Gas Turb. Power 122 (2000), pp. 150-182.

[20] R. Fernández-Prini, J.L. Alvarez and A.H. Harvey, J. Phys. Chem. Ref. Data 32 (2003), pp. 903-916.

[21] B. Beverskog and I. Puigdomenech, Corros. Sci. 39 (1997), pp. 969-980.

[22] N.V. Plyasunova, Y. Zhang and M. Muhammed, Hydrometallurgy 48 (1998), pp. 43-63.

[23] H. Gamjäger, H. Wallner and W. Preis, Monatsh. Chem. 133 (2002), pp. 225-229.

[24] C. Soustelle, M. Foucault, P. Combrade, K. Wolski, T. Magnin, PWSCC of alloy 600: a parametric study of surface film effects, in: Proceedings of the Ninth International Symposium on Environmental Degradation of Materials in Nuclear Power Systems Water Reactors, Newport Beach, USA, 1999.

[25] J. Panter, Etude de la corrosion sous contrainte des alliages 690 et 600 en milieu primaire des REP, Influence des procédés de fabrication des tubes de générateur de vapeur sur la phase d'amorçage, Ph.D. Thesis, Polytechnic National Institute of Toulouse, 2002.

[26] B. Beverskog and I. Puigdomenech, Corros. Sci. 38 (1996), pp. 2121-2135.

[27] P. Berge, Influence des traitements de surface sur la résistance à la corrosion des aciers inoxydables, Ph.D. Thesis, University of Paris, 1968.

[28] Y.L. Sandler and R.H. Kunig, Nucl. Sci. Eng. 64 (1977), pp. 866-874.

[29] Y. Hanzawa, D. Hiroishi, C. Matsuura and K. Ishigure, Nucl. Sci. Eng. 124 (1996), pp. 211-218.

[30] Y. Nishino, T. Sawa, In-situ measurement of $\mathrm{NiFe}_{2} \mathrm{O}_{4}$ formation from iron hydroxides and oxides, in: Proceedings of the JAIF International Conference on Water Chemistry in Nuclear Power Plants - Operational Experience and New Technologies for Management, Tokyo, Japan, 1988. 